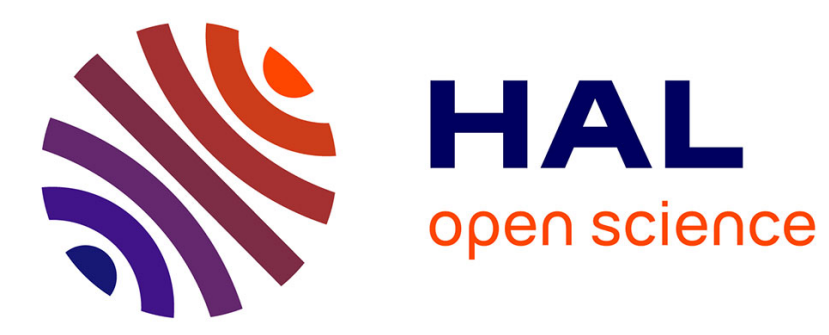

\title{
Fast and efficient synthesis of SSZ-13 by interzeolite conversion of Zeolite Beta and Zeolite L
}

Lingxue Tang, Kok-Giap Haw, Yiying Zhang, Qianrong Fang, Shilun Qiu, Valentin Valtchev

\section{- To cite this version:}

Lingxue Tang, Kok-Giap Haw, Yiying Zhang, Qianrong Fang, Shilun Qiu, et al.. Fast and efficient synthesis of SSZ-13 by interzeolite conversion of Zeolite Beta and Zeolite L. Microporous and Mesoporous Materials, 2019, 280, pp.306-314. 10.1016/j.micromeso.2019.02.021 . hal-02399314

\section{HAL Id: hal-02399314 https://hal.science/hal-02399314}

Submitted on 22 Oct 2021

HAL is a multi-disciplinary open access archive for the deposit and dissemination of scientific research documents, whether they are published or not. The documents may come from teaching and research institutions in France or abroad, or from public or private research centers.
L'archive ouverte pluridisciplinaire HAL, est destinée au dépôt et à la diffusion de documents scientifiques de niveau recherche, publiés ou non, émanant des établissements d'enseignement et de recherche français ou étrangers, des laboratoires publics ou privés.

\section{(ㄷ)(1) $\$$}

Distributed under a Creative Commons Attribution - NonCommerciall 4.0 International 


\title{
Fast and Efficient Synthesis of SSZ-13 by Interzeolite Conversion of Zeolite Beta and
}

\section{Zeolite L}

Lingxue Tang, ${ }^{\text {a }}$ Kok-Giap Haw, ${ }^{\mathrm{a}}$ Yiying Zhang, ${ }^{\mathrm{a}}$ Qianrong Fang, ${ }^{\mathrm{a}}$ Shilun Qiu, ${ }^{\mathrm{a}}$ Valentin Valtchev ${ }^{\mathrm{a}, b^{*}}$

a State Key Laboratory of Inorganic Synthesis and Preparative Chemistry, Jilin University, Changchun 130012, China

${ }^{\mathrm{b}}$ Normandie Univ, ENSICAEN, UNICAEN, CNRS, Laboratoire Catalyse et Spectrochimie, 6 Marechal Juin, 14050 Caen, France

\begin{abstract}
Highly crystalline and pure SSZ-13 zeolite is obtained by interzeolite conversion of zeolite Beta and zeolite L. Zeolite Beta is used without preliminary treatment, while zeolite L is subjected to dealumination in order to reach the Si/Al ratio appropriate for the synthesis of SSZ-13. The formation of SSZ-13 from conventional chemicals is also studied. The crystallization from zeolite precursors is much faster and provides pure and highly crystalline SSZ-13. The improved crystal growth kinetics is attributed to the directing effect of the dissolved Si-O-Al fragments from zeolite Beta and zeolite L frameworks. CHA-type zeolites obtained from dealuminated zeolite L crystallized faster, showed higher crystallinity and more defined crystals morphology in respect to those obtained from zeolite Beta. The dealuminated zeolite L was found to be an outstanding starting material for the crystallization of SSZ-13.
\end{abstract}

Keywords: Zeolite synthesis, Interzeolite conversion, SSZ-13, Crystal growth kinetics. 


\subsection{Introduction}

Zeolites are important industrial catalysts and separation materials thanks to their define micropore structure, high specific surface area, the presence of active sites of different nature and strength and their molecular sieve and ion exchange properties [1-6]. In general, the synthetic zeolites are prepared under hydrothermal conditions from amorphous silica and alumina sources, alkali metal cations and/or organic structure directing agent (SDA). However, alternative methods of synthesis which could improve the zeolite properties or the synthesis process are the focus of continuous research.

The structure commission of International Zeolite Association (IZA) approved 239 zeolite framework types up to now [7], as the number of the new zeolite structures is growing steadily through the years. The CHA-type material, first discovered in nature as mineral Chabazite, is one of the most largely used zeolites. The framework contains ellipsoidal-shaped cages $(6.7 \times 10 \AA)$ connected through a three-dimensional pore system with 8 -membered ring windows $(3.8 \times 3.8 \AA)$. Chabazite can be synthesized as low silica ( $\mathrm{Si} / \mathrm{Al} \sim 2)$ material when solely alkali metals are employed as structure directing agent [8, 9], or as high silica (SSZ-13) material when a specific organic SDA is involved in the synthesis [10]. High silica zeolite is widely used in NOx abatement [11-13], in $\mathrm{CO}_{2} / \mathrm{CH}_{4}$ separation [14] and in Methanol-to-Olefins (MTO) reaction [15-21].

The zeolite formation is a complex process which includes several stages, it starts with the gel formation, followed by the induction period, viable nuclei formation and their growth into crystals [22]. The zeolite nucleation is a spontaneous reaction which takes place after reaching a specific stage of evolution of the amorphous phase [23]. Using alternative initial sources such as crystalline zeolite type materials introduce specific differences in the zeolite formation mechanism [24]. 
During the last decade the potential of hydrothermal conversion of one zeolite into another, i.e., interzeolite transformation from the standpoint of an alternative strategy for zeolite synthesis, was intensively investigated [25-28]. These studies are based on the understanding that locally ordered aluminosilicate species may exist in the conversion process and their assembly under a specific structure-directing agent gives rise to a fast crystallization rate and a high selectivity to a particular zeolite [29-31]. Another advantage of this synthesis route is that the nucleation/crystallization processes can be modified compared to conventional amorphous aluminosilicate gels [32].

The extensive interest to small pore cage-type zeolites and in particular to SSZ-13 motivated us to study the conversion of appropriate zeolites with the goal to optimize the synthesis of this material. This approach has already been used to synthesize aluminosilicates with CHA-type structure. Zones converted GIS-type zeolite to CHA-type material in $\mathrm{NaOH}$ [33]; and Faujasites to high-silica chabazite SSZ-13 in the presence of N, N, N-Trimethyl-l-adamantammonium iodide [34]. Itakura et al. obtained high-silica CHA-type zeolite from FAU-type zeolite in the presence of benzyltrimethylammonium hydroxide [35]. A classic example is the transformation of zeolite Y (FAU-type) into chabazite using a $\mathrm{K}^{+}-\mathrm{Na}^{+}$synthesis solution [36]. Sano and co-workers also used organic template-free system to synthesize chabazite from H-FAU material [37]. The same group discovered a way to synthesize CHA-type from a denser LEV-type structure without using organic SDA [38]. Goel and Ji converted FAU-type to CHA-type without organic SDA [32, 39]. Takata et al. utilizes FAU-type zeolite for hydrothermal conversion in the presence of seed crystals and templating agents to obtain nanosized CHA-type zeolite with high thermal stability and hydrothermal stability [40]. Xiong et al. converted FAU-type zeolite to high silica CHA-type zeolite in the absence of water [41]. Takata et al. successfully transformed 
heterometal-incorporated FAU-type aluminosilicates (M-FAU) to heterometal-incorporated CHA-type aluminosilicate zeolites (M-CHA, M = Fe, Ga, Sn) [42]. Martín et al. synthesized chabazite with high solid yields by the rational combination of directing effects of Si- and Alextracts of USY zeolites and the tetraethylammonium cations [43]. Bhadra et al. converted zeolite FAU-Y to chabazite SSZ-13 in the presence of tetraethylammonium hydroxide [44]. Finally, Geng et al. used zeolite LTA as the aluminum source to rapidly synthesize zeolite SSZ-13 in the presence of colloidal silica, $\mathrm{NaOH}$ and $\mathrm{N}, \mathrm{N}, \mathrm{N}$-trimethyladamantammonium hydroxide [45].

We selected zeolite Beta and zeolite L as starting materials in order to obtain high silica SSZ-13. The choice of zeolite Beta is based to the appropriate Si/Al ratio, while the structural proximity between CHA- and LTL-type zeolites is the reason for the selection of the later as starting material.

Zeolite beta has been extensively used as a substrate for intermediate zeolite conversion. Zones et al. reported the conversion of various zeolites such as B-Beta to B-SSZ-24, B-SSZ-31 and B-SSZ-33, and Al-Beta to Al-SSZ-24 and Al-SSZ-31 in the presence of amantadine cations and its derivatives [46-47]. Kubota et al. [48] and Ahedi et al. [49] also successfully converted Al-Beta and Ti-Beta to Al-SSZ-31 and Ti-SSZ-24, respectively. OU-1 and MTW were synthesized from high silica Beta using tetraethylammonium hydroxide as a structure-directing agent [50]. The use of FAU-type and Beta zeolites as initial silica-alumina source resulted in highly crystalline and pure RUT-type zeolites [51]. Goel et al. converted BEA-type into MFI-type without addition of seed and template [52]. Khan et al. synthesized zeolite SSZ-13 by adding $\mathrm{Na}_{2} \mathrm{SiO}_{3}$ to zeolite Beta [53].

The objective of the present study is optimizing the synthesis of SSZ-13 by using interzeolite 
conversion synthetic approach. By employing two different zeolites, which differ in composition and structure type, we also aim to shed more light on the key factors controlling the interzeolite conversion. Finally, the conversion of zeolite L to SSZ-13 (CHA-type) was not reported to date to the best of our knowledge.

\subsection{Experimental}

\subsection{Materials}

All chemicals and materials used were collected from commercially available sources and used without further purification. The chemicals used in this work are Potassium hydroxide (KOH 98\%, Aladdin Chemistry), Lithium hydroxide (LiOH 98\%, Sigma-Aldrich), Sodium hydroxide ( $\mathrm{NaOH} 98 \%$, Aladdin Chemistry), Cesium hydroxide (CsOH 50 wt\% in water, Adamas-beta), N,N,N-trimethyl-1-adamantammonium (TMAD 98\%, Aladdin Chemistry), deionized water, aluminum powder (99.5\%, Aladdin Chemistry), Sodium nitrate (99.5\%, Aladdin Chemistry), Ludox HS-40 (40 wt\% $\mathrm{SiO}_{2}$, Sigma-Aldrich), and Ludox HS-30 (30 wt\% $\mathrm{SiO}_{2}$, Sigma-Aldrich). $\mathrm{HCl}(12 \%$, Sinopharm Chemical Reagent). The starting zeolite Beta with $\mathrm{Si} / \mathrm{Al}=11$ was purchased from SANBANG Chemicals, China.

\subsection{Synthesis of Zeolite $\mathbf{L}$}

Nanosized zeolite $\mathrm{L}$ was synthesized using the following molar composition $1 \mathrm{SiO}_{2}: 0.05 \mathrm{Al}_{2} \mathrm{O}_{3}: 0.5 \mathrm{~K}_{2} \mathrm{O}: 20 \mathrm{H}_{2} \mathrm{O}$. The potassium solution was prepared by dissolving $6.580 \mathrm{~g}$ of $\mathrm{KOH}$ in $20.216 \mathrm{~g}$ deionized water in an ice bath, then $0.273 \mathrm{~g}$ of aluminum powder was added. The mixture was stirred for 15 min to obtain a clear solution. $20.09 \mathrm{~g}$ of Ludox HS-30 was then added 
and the mixture was stirred for $10 \mathrm{~min}$. The resulting solution was then transferred into a $30 \mathrm{~mL}$ teflon-lined autoclave. The hydrothermal treatment was performed at $170{ }^{\circ} \mathrm{C}$ for $16 \mathrm{~h}$ in an oven under static condition. The sample was collected by centrifugation and washed with deionized water until a near neutral $\mathrm{pH}$ was achieved, and then dried overnight at $60{ }^{\circ} \mathrm{C}$.

\subsection{Dealumination of Zeolite $\mathbf{L}$}

Zeolite $\mathrm{L}$ with $\mathrm{Si} / \mathrm{Al}$ ratio equal to $11,22,26$ and 77 was prepared by dealumination of the nanosized zeolite $\mathrm{L}(\mathrm{Si} / \mathrm{Al}=3)$. Hydrochloric $(\mathrm{HCl})$ acid with concentration of $0.48 \mathrm{M}, 0.49 \mathrm{M}$, 0.50 M, 1.00 M was used. The dealumination was performed at $25^{\circ} \mathrm{C}$ for $4 \mathrm{~h}$ under stirring. The liquid:solid weight ratio was 30 . The solid was collected by centrifugation, thoroughly washed with deionized water to $\mathrm{pH} \sim 7$ and dried overnight at $60{ }^{\circ} \mathrm{C}$.

\subsection{Synthesis of SSZ-13}

The two materials (zeolite Beta and zeolite L) were hydrothermally converted to SSZ-13 using $\mathrm{N}, \mathrm{N}, \mathrm{N}$-trimethyl-1-adamantammonium (TMAD) as a structure directing agent. Gel molar composition was $\mathrm{xMOH}: y \mathrm{TMAD}: \mathrm{zH}_{2} \mathrm{O}$, where $\mathrm{M}$ is $\mathrm{Na}, \mathrm{K}, \mathrm{Li}, \mathrm{Cs}, \mathrm{x}=0.3-0.5, \mathrm{y}=0.2-0.3$ and $\mathrm{z}=20$ and 30 for zeolite $\mathrm{L}$ and zeolite Beta conversion, respectively. Zeolite Beta and zeolite L were used as silicon and aluminum sources and no additional $\mathrm{SiO}_{2}$ or $\mathrm{Al}_{2} \mathrm{O}_{3}$ was added to the gel. In a typical experiment, $1.7 \mathrm{~g}$ zeolite beta and the TMAD solution were mixed (solid/liquid weight ratio $=0.14$ ) under stirring for $2 \mathrm{~h}$ at room temperature. $1.3 \mathrm{~g}$ zeolite $\mathrm{L}$ and the TMAD solution were mixed (solid/liquid weight ratio $=0.16$ ) under stirring for $2 \mathrm{~h}$ at room temperature. The optimized compositions of the systems used for transformation of zeolite L (CL) and zeolite Beta 
(CB) was as follows:

$$
\begin{aligned}
& \text { CL: } 1 \mathrm{SiO}_{2}: 0.0455 \mathrm{Al}_{2} \mathrm{O}_{3}: 0.19 \mathrm{~K}_{2} \mathrm{O}: 0.26 \mathrm{TMAD}: 20 \mathrm{H}_{2} \mathrm{O} \text {; } \\
& \text { CB: } 1 \mathrm{SiO}_{2}: 0.0455 \mathrm{Al}_{2} \mathrm{O}_{3}: 0.18 \mathrm{~K}_{2} \mathrm{O}: 0.31 \mathrm{TMAD}: 30 \mathrm{H}_{2} \mathrm{O} \text {. }
\end{aligned}
$$

The $\mathrm{SiO}_{2} / \mathrm{Al}_{2} \mathrm{O}_{3}$ ratio (zeolite $\mathrm{L}$ and zeolite Beta) of two systems is similar, but they differ in water, $\mathrm{K}^{+}$and TMAD content, which was necessary in order to get pure SSZ-13. After homogenization, the mixture was transferred in a $30 \mathrm{~mL}$ Teflon-lined stainless-steel autoclave. The hydrothermal conversion was carried out at $150{ }^{\circ} \mathrm{C}$ and $180{ }^{\circ} \mathrm{C}$ in an electric oven. After crystallization step, the solid product was collected by vacuum filtration and washed thoroughly with deionized water until a near neutral $\mathrm{pH}$ and then dried overnight at $60{ }^{\circ} \mathrm{C}$.

Reference SSZ-13 samples were synthesized using conventional chemicals and preparing gels with chemical compositions similar to $\mathrm{CB}$ and CL systems. The two systems corresponding to the zeolite L (CC-1) and zeolite Beta (CC-2) conversion exhibit the following molar composition:

$$
\begin{aligned}
& \text { CC-1: } 1 \mathrm{SiO}_{2}: 0.05 \mathrm{Al}_{2} \mathrm{O}_{3}: 0.19 \mathrm{~K}_{2} \mathrm{O}: 0.26 \mathrm{TMAD}: 20 \mathrm{H}_{2} \mathrm{O} \text {; } \\
& \text { CC-2: } 1 \mathrm{SiO}_{2}: 0.05 \mathrm{Al}_{2} \mathrm{O}_{3}: 0.18 \mathrm{~K}_{2} \mathrm{O}: 0.31 \mathrm{TMAD}: 30 \mathrm{H}_{2} \mathrm{O} \text {. }
\end{aligned}
$$

Ludox HS-40 and alunimum powder were employed as silicon and aluminum source, respectively. $\mathrm{CC}-1$ was prepared by dissolution of $0.62 \mathrm{~g}$ of $\mathrm{KOH}$ in $7.6 \mathrm{~g}$ deionized water, then $0.072 \mathrm{~g}$ of aluminum powder was added. The mixture was stirred for $15 \mathrm{~min}$ to obtain a clear solution. $1.62 \mathrm{~g}$ of TMAD was added and the mixture was stirred for $10 \mathrm{~min} .4 .43 \mathrm{~g}$ of Ludox HS-40 was then added and the mixture was stirred for $24 \mathrm{~h}$ at ambient temperature. CC-2 was prepared by dissolution of $0.6 \mathrm{~g}$ of $\mathrm{KOH}$ in $10.55 \mathrm{~g}$ deionized water, then $0.072 \mathrm{~g}$ of aluminum powder was added. The mixture was stirred for $15 \mathrm{~min}$ to obtain a clear solution. $1.95 \mathrm{~g}$ of TMAD was added to the mixture and stirred for $10 \mathrm{~min} .4 .43 \mathrm{~g}$ of Ludox HS-40 was then added and the 
mixture was stirred for $24 \mathrm{~h}$ at ambient temperature. The mixture was then transferred into a $30 \mathrm{~mL}$ Teflon-lined autoclave and hydrothermally treated at $150{ }^{\circ} \mathrm{C}$ for $24 \mathrm{~h}$ and $72 \mathrm{~h}$ in an oven under static condition. Then, the sample was collected by vacuum filtration and washed with deionized water until a near neutral $\mathrm{pH}$ and dried overnight at $60^{\circ} \mathrm{C}$.

\subsection{Characterization}

All materials were characterized by Powder X-ray diffraction (PXRD) analysis using a PANalytical B.V. Empyrean powder diffractometer with $\mathrm{Cu} \mathrm{K}_{\alpha}$ radiation $(\lambda=1.5418 \AA$ ) operating at $40 \mathrm{kV}$ and $40 \mathrm{~mA}$. XRD diffraction analysis was used to study the crystals growth kinetics of SSZ-13 zeolite. The kinetics of conversion was determined by the surface of the peak at $9.3^{\circ}$ Two Theta. SSZ-13 prepared according to ref. 8 was used as a reference sample. Thermogravimetric analysis (TGA) was performed on a SHIMADZU DTG-60 thermal analyzer system. Approximately $10 \mathrm{mg}$ of each sample was introduced in an alumina crucible and loaded in the analyzer chamber. The samples were heated from 30 to $700{ }^{\circ} \mathrm{C}$ with a heating ramp of $10{ }^{\circ} \mathrm{C} \cdot \mathrm{min}^{-1}$ under air (flow rate: $40 \mathrm{~mL} \cdot \mathrm{min}^{-1}$ ). Scanning electron microscopy (SEM) micrographs were taken on a JEOL JSM7400F microscope operated at 3-10 keV and $10 \mu \mathrm{A}$. Transmission electron microscopy (TEM) analysis was performed on a JEM-2100F. Prior to the measurement, a diluted colloidal suspension of sample was sonicated for $5 \mathrm{~min}$ and then dropped on a carbon-film-covered 300-mesh copper electron microscope grids and dried. Elemental analysis of the sample was measured by Energy Dispersive X-Ray Fluorescence Spectrometer (EDX) operated under TEM (JEM-2100F). Nitrogen adsorption measurements were performed on a Micromeritics ASAP 2040 surface area analyzer. The calcined samples were analyzed after degassing at $300{ }^{\circ} \mathrm{C}$. The 
isotherms were recorded using ASAP 2040 analysis program. The microporous volume $\left(V_{\mathrm{mic}}, \mathrm{cm}^{3}\right.$ $\mathrm{g}^{-1}$ ) was obtained from t-plot based on the Harkins-Jura equation.

\subsection{Results and Discussion}

\subsection{Physicochemical characterization of initial zeolites}

Zeolite Beta and zeolite L used as initial silica-alumina sources do not contain impurities (Figure S1). The TEM inspection showed that both samples contain nanosized crystals building complex aggregates (Figure S2). Nitrogen adsorption isotherms are characteristic of nanosized zeolite materials. The fast uptake at low relative pressure is followed by moderate inclination of isotherm in the $0.2-0.8 \mathrm{P} / \mathrm{P}_{\mathrm{o}}$ range and second uptake at high relative pressure (Figure $\mathrm{S} 3$ ). These features are due to the textural porosity generated by the aggregation of nanosized zeolite Beta and zeolite L crystals. The micropore volume and $S_{\text {BET }}$ of zeolite Beta was $0.18 \mathrm{~cm}^{3} \mathrm{~g}^{-1}$ and $520 \mathrm{~m}^{2} \mathrm{~g}^{-1}$, respectively. Zeolite $\mathrm{L}$ showed micropore volume and $S_{\mathrm{BET}}$ of $0.13 \mathrm{~cm}^{3} \mathrm{~g}^{-1}$ and $438 \mathrm{~m}^{2} \mathrm{~g}^{-1}$, respectively. The $\mathrm{Si} / \mathrm{Al}$ ratio of zeolite Beta was 11 , which is appropriate for the synthesis of SSZ-13. The Si/Al ratio zeolite $\mathrm{L}$ was 3, which required a dealumination step in order to reach the range appropriate for the synthesis of SSZ-13.

\subsection{Dealumination of zeolite $L$ and its conversion to SSZ-13}

The XRD patterns of dealuminated zeolite L samples are shown in Figure 1a. Only a halo revealing the amorphization of the zeolite and the peak at $5.5^{\circ}$ Two Theta can be observed. It is worth noting that the dealumination with $\mathrm{HCl}$ is quite efficient, even a small change in the $\mathrm{HCl}$ concentration $(0.48-0.50 \mathrm{M})$ changed the $\mathrm{Si} / \mathrm{Al}$ ratio substantially. The chemical analysis of 
treated sample showed that the $\mathrm{Si} / \mathrm{Al}$ ratio increases from 3 in the parent zeolite to 11,21, 26 and 77 after dealuminated in $0.48,0.49,0.50$ and $1.0 \mathrm{M} \mathrm{HCl}$, respectively (Figure $1 \mathrm{~b}$ ).

The initial zeolite $\mathrm{L}(\mathrm{Si} / \mathrm{Al}=3$, run $\mathrm{CL}-7)$ was subjected to hydrothermal treatment at $150{ }^{\circ} \mathrm{C}$ for $24 \mathrm{~h}$ (Table 1). The zeolite remained intact after the hydrothermal treatment (Figure 2a). In contrast, all dealuminated samples were hydrothermally transformed and no trace of zeolite L was observed in the products. The level of zeolite L dealumination strongly influenced the formation of SSZ-13. Thus, the highly dealuminated material $(\mathrm{Si} / \mathrm{Al}=77)$ does not yield CHA-type zeolite. Instead, a layer type material was synthesized, which reveals the importance of the initial Si/Al ratio for the successful synthesis of SSZ-13. The other three sources were successfully converted in SSZ-13 as X-ray crystallinity of the products was similar (Figure 2a). The silica-alumina conversion for all SSZ-13 was about $40 \%$. On the other hand, the framework composition of SSZ-13 was influenced by the initial zeolite L. Thus, the dealuminated samples with Si/Al ratio 11 and 21 yielded zeolites with $\mathrm{Si} / \mathrm{Al}$ ratio of 6.7 and 7.5 respectively. For sample with $\mathrm{Si} / \mathrm{Al}=26$, SSZ-13 with Si/Al = 16 was formed. In general, the crystalline product exhibits a Si/Al ratio lower than the dealuminated zeolite $\mathrm{L}$.

The nitrogen adsorption isotherm of CHA-type zeolites obtained from dealuminated zeolite L is type I. Negligible differences between the three samples are observed (Table 1). The micropore volume of the samples corresponds to highly crystalline CHA-type zeolite confirming the high quality of the materials obtained from zeolite L. Fairly similar in size and crystal morphology SSZ-13 was obtained from the dealuminated zeolite L sources (Figure S4). Individual well-shaped crystals with the typical rectangular morphology were yielded, no matter of the Si/Al ratio of the dealuminated zeolite L. 
In summary, the dealuminated zeolite L is an appropriate source for the synthesis of SSZ-13. Further, we selected the source with $\mathrm{Si} / \mathrm{Al}=11$ for a more detail investigation of the crystallization process. This selection is justified by the high crystallinity of the obtained SSZ-13 and the similar $\mathrm{Si} / \mathrm{Al}$ ratio with the zeolite Beta source, which allowed comparing the efficiency of two zeolites in the production of SSZ-13.

\subsection{Comparative study of zeolite Beta and zeolite $L$ conversion to SSZ-13}

The reaction conditions and the results of zeolite Beta and zeolite L hydrothermal conversion at $150{ }^{\circ} \mathrm{C}$ and $180^{\circ} \mathrm{C}$ are summarized in Table 2 . The preliminary experiments allowed to optimize the synthesis conditions so as to use a close ratio between the reactants used to convert zeolite Beta and Zeolite L to SSZ-13. CHA-type zeolites were successfully obtained from both zeolite Beta and zeolite $\mathrm{L}$ with $\mathrm{Si} / \mathrm{Al}$ ratios of 11 . However, the ratio between components of the starting mixture plays an important role. For instance, the $\mathrm{KOH} / \mathrm{SiO}_{2}$ ratio is crucial for the conversion of zeolite Beta into SSZ-13 and for the purity of the final product. Thus at $\mathrm{KOH} / \mathrm{SiO}_{2}=0.2$ no formation of SSZ-13 after 24 h crystallization at $150{ }^{\circ} \mathrm{C}$ was observed. Highly crystalline SSZ-13 was obtained at both temperature $150{ }^{\circ} \mathrm{C}$ and $180{ }^{\circ} \mathrm{C}$ when a gel with $\mathrm{KOH} / \mathrm{SiO}_{2}=0.36$ was used. The crystallization was much faster at $180{ }^{\circ} \mathrm{C}$, where a substantial conversion of zeolite Beta into SSZ-13 was observed after $4 \mathrm{~h}$ crystallization (CB-5). After $8 \mathrm{~h}$ the same system gave high crystalline SSZ-13 (CB-6). The extension of synthesis time to $10 \mathrm{~h}$ did not improve the crystallinity of the product, showing that the conversion is almost completed after $8 \mathrm{~h}$. The increase of the $\mathrm{KOH} / \mathrm{SiO}_{2}$ to 0.5 and 0.6 resulted in a mixture of SSZ-13 and Mordenite.

In the case of zeolite $\mathrm{L}$ conversion the $\mathrm{KOH} / \mathrm{SiO}_{2}$ ratio of 0.38 was found to be the most 
appropriate for the formation of SSZ-13. A ratio of $\mathrm{TMAD} / \mathrm{SiO}_{2}=0.26$ was used in most of the synthesis with dealuminated zeolite L. Highly crystalline SSZ-13 was obtained at both temperatures, $150{ }^{\circ} \mathrm{C}$ and $180{ }^{\circ} \mathrm{C}$. The crystallization at $180{ }^{\circ} \mathrm{C}$ was much faster, after only $4 \mathrm{~h}$ the product contained some amount of SSZ-13 plus amorphous material. After 8 and $10 \mathrm{~h}$ synthesis the system yielded pure and highly crystalline CHA-type zeolite. It took $24 \mathrm{~h}$ in order to obtain highly crystalline from the same initial system at $150{ }^{\circ} \mathrm{C}$, which is still substantially faster than the conventional synthesis of SSZ-13. A similar initial system prepared from conventional reactants took $72 \mathrm{~h}$ to obtained highly crystalline SSZ-13. The crystalline yield was calculated by $\mathrm{SiO}_{2}+$ $\mathrm{Al}_{2} \mathrm{O}_{3}$ in the initial system. The highest conversions $(\mathrm{CC}-1=66 \%$ and $\mathrm{CC}-2=77 \%)$ was recorded for the systems prepare from conventional reactants. The conversion of zeolite Beta to SSZ-13 varied from 45 to $59 \%$ in different syntheses, while the one from zeolite L was between 50 and $53 \%$.

Figure 3 provides a more detail picture of the transformation of two zeolites in SSZ-13. XRD patterns of the products obtained at $150{ }^{\circ} \mathrm{C}$ from zeolite Beta and zeolite L are presented in Figure 3a and 3b, respectively. A decrease of crystallinity of zeolite Beta and first traces of SSZ-13 are observed after $4 \mathrm{~h}$ hydrothermal treatment. The crystallinity increased with time and reached the maximum after $24 \mathrm{~h}$. It is worth noting that no amorphous intermediate, i.e. a halo, was detected by XRD. Dealuminated zeolite L precursors reacted faster with the synthesis solution. After $1 \mathrm{~h}$ treatment traces of zeolite L were observed and first CHA-type material was recorded after $3 \mathrm{~h}$ hydrothermal conversion (Figure 3b). With the extension of the synthesis time, the crystallinity increased and fully crystalline solid was obtained after $24 \mathrm{~h}$. The transformation of zeolite $\mathrm{L}$ to the CHA-type material was different from zeolite Beta. It includes two steps process, first an 
intermediate amorphous phase was formed which was converted to CHA-type zeolite.

The physical transformation of two zeolites to SSZ-13 was followed by SEM. Both products contain rectangular well shaped crystals typical of CHA-type material. Up to 10 h hydrothermal treatment, the products contain aggregates of small particles, which are non reacted zeolite Beta and amorphous zeolite L precursor respectively. After this stage, only the rectangular crystals of SSZ-13 can be seen. The product obtained by conversion of zeolite $\mathrm{L}$ is more uniform with $2-3 \mu \mathrm{m}$ crystals (Figure 4), while the one synthesized by conversion of zeolite Beta contains two populations of crystals with size 1-2 and 4-5 $\mu \mathrm{m}$ (Figure 5).

Conventional reactants were used to prepare initial systems similar to those used for zeolite Beta and zeolite L conversion to SSZ-13. The syntheses were performed at $150{ }^{\circ} \mathrm{C}$ and resulted in highly crystalline SSZ-13 (Figure 6 left). However, both products contained mordenite. The amount of mordenite was at detection limit in the system corresponding to zeolite L conversion, while larger amount (ca. $10 \%$ ) was found in the system corresponding to zeolite Beta conversion. Three days were necessary to reach a full conversion of amorphous silica-alumina sources. The SEM inspection of the CC-1 crystalline product showed the typical rectangular morphology of the product (Figure 6 right). Product with similar size and crystal size distribution was obtained in the CC-2 system. As can be seen the uniformity of the products is lower than those synthesized via interzeolite conversion. All these features show that the zeolite precursors are more efficient source for the synthesis of SSZ-13.

The highly crystalline sample obtained from zeolite L (CL-3) and zeolite Beta (CB-3) were subjected to physicochemical analysis to study their properties. The two samples showed similar thermogravimetrical profiles with a total weight loss of $22 \mathrm{wt} . \%$ and $21 \mathrm{wt} . \%$ for CB-3 and CL-3, 
respectively (Figure 7). CB-3 exhibited higher weight lost (5.5 wt.\%) in the low temperature range $\left(25-200{ }^{\circ} \mathrm{C}\right)$ revealing higher water content, while the amount of the structure directing agent decomposed at high temperature $\left(400-650{ }^{\circ} \mathrm{C}\right)$ was lower. SSZ-13 synthesized from conventional chemicals showed similar weight loss in the low temperature range, but lower weight loss in the range where the organic structure directing agent is released (Figure 7). CL-3 released about 2 wt. $\%$ water below $200{ }^{\circ} \mathrm{C}$, while the content of the template was about $18 \mathrm{wt} . \%$. The huge weight loss between $400{ }^{\circ} \mathrm{C}$ and $650{ }^{\circ} \mathrm{C}$ corresponded to the decomposition of TMAD. The two zeolites showed similar Si/Al ratio, 7.2 and 6.7 for $\mathrm{CB}-3$ and CL-3, respectively. Therefore, the difference in water content cannot be attributed to the differences in the chemical composition and hydrophilic-hydrophobic properties. Hence, the most plausible explanation is differences in the crystallinity, which is difficult to be detected by the XRD analysis. Physisorption measurements confirmed this hypothesis. The micropore volume $\left(0.26 \mathrm{~cm}^{3} \mathrm{~g}^{-1}\right)$ and $S_{\text {BET }}$ area $\left(526.0 \mathrm{~m}^{2} \mathrm{~g}^{-1}\right)$ of CL-3 are substantially higher in respect to CB-3 $\left(0.23 \mathrm{~cm}^{3} \mathrm{~g}^{-1} ; 489 \mathrm{~m}^{2} \mathrm{~g}^{-1}\right)$ revealing higher crystallinity of SSZ-13 obtained from zeolite L. As can be seen in Figure S5, the low pressure uptake of CL-3 is higher than that of CB-3. The two isotherms are type I with negligible hysteresis loop. As shown in Figures 4 and 5, the SSZ-13 crystals are well shaped with limited intergrowth between the particles. Consequently, the amount of mesopores is very limited in the material.

\subsection{Effect of alkali metal cation on the SSZ-13 formation}

Since the alkali metal cation plays an essential role in the zeolite synthesis, the effect of $\mathrm{Li}^{+}$, $\mathrm{Na}^{+}, \mathrm{K}^{+}, \mathrm{Cs}^{+}$on the formation of SSZ-13 was studied. Zeolite Beta and zeolite L precursors with $\mathrm{Si} / \mathrm{Al}$ ratio 11 were used in this series of experiments. TMAD was employed as organic structure 
directing agent. Alkali metal and $\mathrm{TMAD} / \mathrm{SiO}_{2}$ contents differ slightly in the systems used for the conversion of zeolite Beta and zeolite L, which was necessary in order to adapt the synthesis solution to the particularities of the zeolite precursor. The results are summarized in Table 3 .

XRD patterns of the obtained products are presented in Figure S6. Zeolite Beta and zeolite L were successfully converted to SSZ-13 in the presence of sodium and potassium. These two cations are equally efficient in the formation of CHA-type material. The products showed similar crystallinity and particle size. The crystalline products synthesized from zeolite Beta and zeolite L employing $\mathrm{Na}$ as alkali cation showed similarities in terms of crystallinity and particle size (2-3 $\mu \mathrm{m})$. The only difference is that the crystals obtained from zeolite Beta are well shaped, whereas more spherical crystals are obtained from zeolite L (Figure S7). The use of Li resulted in the formation of unknown crystalline phase, no matter zeolite Beta or zeolite L is used in the synthesis. The difference between the products synthesized with $\mathrm{Li}$ is that zeolite Beta is largely present in the solid product, while no trace of zeolite $\mathrm{L}$ was found. This result is expectable having in mind lower stability of dealuminated zeolite L. The use of Cs resulted in the formation of Pollucite with both, zeolite Beta and zeolite L sources. These set of experimental results points out the importance of the alkali metal cation in the formation of CHA-type aluminosilicates. Although an efficient structure directing agent was employed, the presence of $\mathrm{Li}$ and $\mathrm{Cs}$ changed the crystallization pathway and resulted in the formation of undesired products. On the other hand, no significant difference in the impact of $\mathrm{Na}$ and $\mathrm{K}$ on the formation of SSZ-13 was found.

\subsection{Kinetics and mechanism of zeolite transformation}

Previous studies showed that the interzeolite conversion is strongly influenced by the structural 
similarities of zeolite used as a source of nutrients and the synthesized zeolite.[50] CHA- and LTL-type structures have obvious similarities, both are built exclusively of 4- and 6-member rings and the double 6-member rings (D6R) are mostly present. Zeolite beta contains 4- and 6-member rings, but the 5-member ring is the main structural unit, which place the zeolite in the family of pentasils. Nevertheless, zeolite Beta was successfully converted in SSZ-13.

In order to gain more insight in the transformation process we have studied the crystal growth kinetics of SSZ-13 at $150{ }^{\circ} \mathrm{C}$ and $180{ }^{\circ} \mathrm{C}$ using zeolite Beta $(\mathrm{Si} / \mathrm{Al}=11)$ and dealuminated zeolite $\mathrm{L}$ $(\mathrm{Si} / \mathrm{Al}=11)$ as initial silica-alumina source. A substantial difference in the transformation of zeolite L and zeolite Beta to SSZ-13 was observed at $150{ }^{\circ} \mathrm{C}$ (Figure 8a). The zeolite L source was completely converted in CHA-type zeolite within $8 \mathrm{~h}$, while $18 \mathrm{~h}$ were necessary to re-crystallized zeolite Beta. Since the $\mathrm{Si} / \mathrm{Al}$ ratio of the two sources is similar we attribute the observed difference to the structural similarity between LTL- and CHA-type zeolites. It should be added that the structure of zeolite L was partially destroyed by the dealumination, which certainly increases its reactivity. In contrast, no difference between the transformation of zeolite L and zeolite Beta at $180{ }^{\circ} \mathrm{C}$ was observed (Figure $8 \mathrm{~b}$ ). The crystallization was completed within $8 \mathrm{~h}$. Our interpretation of this result is that at high temperature the initial zeolite sources are rapidly dissolved, and thus the impact of structural units originating from the parent zeolite is decreased. The impact is decreased but not completely lost since the formation of SSZ-13 from these two zeolite sources is still faster in respect to a conventional synthesis involving amorphous silica-alumina sources.

\subsection{Conclusion}

A detailed investigation of interzeolite conversion of zeolite Beta and zeolite L to SSZ-13 
(CHA-type) in the presence of TMAD as SDA was performed. Zeolite Beta was used without preliminary pretreatment, while zeolite $\mathrm{L}$ was subjected to dealumination to reach a $\mathrm{Si} / \mathrm{Al}$ ratio appropriate for the formation of SSZ-13. After optimization of synthesis conditions both zeolites, Beta and L, yielded pure and highly crystalline SSZ-13. The formation of SSZ-13 from these zeolite precursors was substantially faster than that from a conventional gel with a similar composition. The comparative study of the transformation of two zeolites showed that dealuminated zeolite Lis a more efficient precursor for the synthesis of SSZ-13. The growth rate of SSZ-13 yielded from dealuminated zeolite L is faster and the product shows higher crystallinity, which is attributed to the great similarities of LTL- and CHA-type structures. Thus, our data fully support the importance of structural similarity between zeolite source and zeolite product in the interzeolite conversion. In summary, this study provides a facile and rapid way for the synthesis of SSZ-13, an industrially relevant zeolite with great impact in environmental protection and low olefins synthesis.

\subsection{Acknowledgements}

Q.F. and V.V. thank the National Natural Science Foundation of China $(21571079,21621001$, 21390394, 21571076 and 21571078) for financial support. Q.F and V.V. acknowledge the support from Thousand Talents program (China).

\subsection{References}

[1] C. Martínez and A. Corma, Coordin. Chem. Rev. 255 (2011) 1558-1580.

[2] J. Gascon, F. Kapteijn, B. Zornoza, V. Sebastian, C. Casadoand J. Coronas, Chem. Mater. 24 
(2012) 2829-2844.

[3] N. Kosinov, C. Auffret, V. G. Sripathi, C. Gücüyener, J. Gascon, F. Kapteijn and E. J. Hensen, Micropor. Mesopor. Mat. 197 (2014) 268-277.

[4] M. Mofarahi and F. Gholipour, Micropor. Mesopor. Mat. 200 (2014) 1-10.

[5] A. Primo and H. Garcia, Chem. Soc. Rev. 43 (2014) 7548-7561.

[6] K. Li, J. Valla and J. Garcia-Martinez, ChemCatChem. 6 (2014) 46-66.

[7] International Zeolite Association Web site:_http: //www.iza-on-line.org/ .

[8] H. Robson, Verified synthesis of zeolitic materials, Gulf Professional Publishing, 2001.

[9] B. Liu, Y. Zheng, N. Hu, T. Gui, Y. Li, F. Zhang, R. Zhou, X. Chen and H. Kita, Micropor. Mesopor. Mat. 196 (2014) 270-276.

[10] S. I. Zones, U.S. Patent 4544538, 1985.

[11] D. W. Fickel, E. D’Addio, J. A. Lauterbach and R. F. Lobo, Appl. Catal. B-Environ. 102 (2011) 441-448.

[12] F. Gao, Y. Wang, M. N. M. Kollár, Washton, J. Szanyi and C. H. Peden, Catal. Today. 258 (2015) 347-358.

[13] F. Gao, M. Kollár, R. K. Kukkadapu, N. M. Washton, Y. Wang, J. Szanyi and C. H. Peden, Appl. Catal. B-Environ. 164 (2015) 407-419.

[14] J. Shang, G. Li, R. Singh, Q. Gu, K. M. Nairn, T. J. Bastow, N. Medhekar, C. M. Doherty, A. J. Hill, J. Z. Liu and P. A. Webley, J. Am. Chem. Soc. 134 (2012) 19246-19253.

[15] Q. Zhu, J. N. Kondo, T. Tatsumi, S. Inagaki, R. Ohnuma, Y. Kubota, Y. Shimodaira, H. Kobayashi and K. Domen, J. Phys. Chem. C. 111 (2007) 5409-5415.

[16] P. Tian, Y. Wei, M. Ye and Z. Liu, ACS Catal. 5 (2015) 1922-1938. 
[17] M. Dusselier, M. A. Deimund, J. E. Schmidt and M. E. Davis, ACS Catal. 5 (2015) 6078-6085.

[18] M. A. Deimund, L. Harrison, J. D. Lunn, Y. Liu, A. Malek, R. Shayib and M. E. Davis, ACS Catal. 6 (2015) 542-550.

[19] Q. Zhu, J. N. Kondo, R. Ohnuma, Y. Kubota, M. Yamaguchi and T. Tatsumi, Micropor. Mesopor. Mat. 112 (2008) 153-161.

[20] Q. Zhu, Kondo, S. Inagaki and T. Tatsumi, Top. Catal. 52 (2009) 1272-1280.

[21] M. Itakura, T. Inoue, A. Takahashi, T. Fujitani, Y. Oumi and T. Sano, Chem. Lett. 37 (2008) 908-909.

[22] M. Smaihi, O. Barida and V. Valtchev, Eur. J. Inorg. Chem. 2003 (2003) 4370-4377.

[23] D. W. Breck, Zeolite Molecular Sieves: Structure, Chemistry and Use, John Wiley and Sons. Inc., New York, Malabar, Florida, 1974.

[24] T. Sano, M. Itakura and M. Sadakane, J. Jpn. Petrol. Inst. 56 (2013) 183-197.

[25] H. Jon, K. Nakahata, B. Lu, Y. Oumi and T. Sano, Micropor. Mesopor. Mat. 96 (2006) 72-78.

[26] T. Inoue, M. Itakura, H. Jon, Y. Oumi, A. Takahashi, T. Fujitani and T. Sano, Micropor. Mesopor. Mat. 122 (2009) 149-154.

[27] I. Goto, M. Itakura, S. Shibata, K. Honda, Y. Ide, M. Sadakane and T. Sano, Micropor. Mesopor. Mat. 158 (2012) 117-122.

[28] K. Honda, M. Itakura, Y. Matsuura, A. Onda, Y. Ide, M. Sadakane and T. Sano, J. Nanosci. Nanotechno. 13 (2013) 3020-3026.

[29] C. S. Cundy and P. A. Cox, Micropor. Mesopor. Mat. 82 (2005) 1-78.

[30] S. Xie, S. Liu, N. Gao, X. Li, Y. Gao, K. Liu and L. Xu, New. J. Chem. 38 (2014) 
2514-2521.

[31] S. Goel, S. I. Zones and E. Iglesia, J. Am. Chem. Soc.136 (2014), 15280-15290.

[32] Y. Ji, M. A. Deimund, Y. Bhawe and M. E. Davis, ACS Catal. 5 (2015) 4456-4465.

[33] S. I. Zones and R. A. Van Nordstrand, Zeolites. 8 (1988) 166-174.

[34] S. I. Zones, J. Chem. Soc. 87 (1991) 3709-3716.

[35] M. Itakura, T. Inoue, A. Takahashi, T. Fujitani, Y. Oum and T. Sano, Chem. Lett. 37 (2008) 908-909.

[36] L. Van Tendeloo, E. Gobechiya, E. Breynaert, J. A. Martens and C. E. Kirschhock, Chem. Commun. 49 (2013) 11737-11739.

[37] M. Itakura, I. Goto, A. Takahashi, T. Fujitani, Y. Ide, M. Sadakane and T. Sano, Micropor. Mesopor. Mat. 144 (2011) 91-96.

[38] I. Goto, M. Itakura, S. Shibata, K. Honda, Y. Ide, M. Sadakane and T. Sano, Micropor. Mesopor. Mat. 158 (2012) 117-122.

[39] S. Goel, S. I. Zones and E. Iglesia, Chem. Mater. 27 (2015) 2056-2066.

[40] T. Takata, N. Tsunoji, Y. Takamitsu, M. Sadakane and T. Sano, Micropor. Mesopor. Mat. 225 (2016) 524-533.

[41] X. Xiong, D. Yuan, Q. Wu, F. Chen, X. Meng, R. Lv, D. Dai, S. Maurer, R. McGuire, M. Feyen, U. Müller, W. Zhang, T. Yokoi, X. Bao, H. Gies, B. Marler, D. E. De Vos, U. Kolb, A. Moini and F.S. Xiao, J. Mater. Chem. A. 5 (2017) 9076-9080.

[42] T. Takata, N. Tsunoji, Y. Takamitsu, M. Sadakane and T. Sano, Micropor. Mesopor. Mat. 246 (2017) 89-101.

[43] N. Martín, M. Moliner and A. Corma, Chem. Commun. 51 (2015) 9965-9968. 
[44] B. N. Bhadra, P. W. Seo, N. A. Khan, J. W. Jun, T. W. Kim, C. U. Kim and S. H. Jhung, Catal. Today. 298 (2017) 53-60.

[45] H. Geng, G. Li, D. Liu and C. Liu, J. Solid. State. Chem. 265 (2018) 193-199.

[46] S. I. Zones, L. T. Yuen, Y. Nakagawa, R. A. Van Nordstrand and S. D. Toto, In Proceedings of the 9th International Zeolites Conference (1993) 163-170.

[47] S. I. Zones and Y. Nakagawa, Micropor. Mesopor. Mat. 101 (2007) 115-126.

[48] H. Maekawa, Y. Kubota and Y. Sugi, Chem. Lett. 33 (2004) 1126-1127.

[49] R. K. Ahedi, Y. Kubota and Y. Sugi, B. Chem. Soc. Jpn. 76 (2003) 883-890.

[50] P. H. P. Rao, K. Ueyama, E. Kikuchi and M. Matsukata, Chem. Lett. 27 (1998) 311-312.

[51] M. Itakura, K. Ota, S. Shibata, T. Inoue, Y. Ide, M. Sadakane and T. Sano, J. Cryst. Growth. 314 (2011) 274-278.

[52] S. Goel, S. I. Zones and E. Iglesia, J. Am. Chem. Soc. 136 (2014) 15280-15290.

[53] N. A. Khan, D. K. Yoo, B. N. Bhadra, J. W. Jun, T. W. Kim, C. U. Kim and S. H. Jhung, Chem. Eng. J. In Press, DOI: 10.1016/j.cej.2018.07.148. 


\section{Figures}
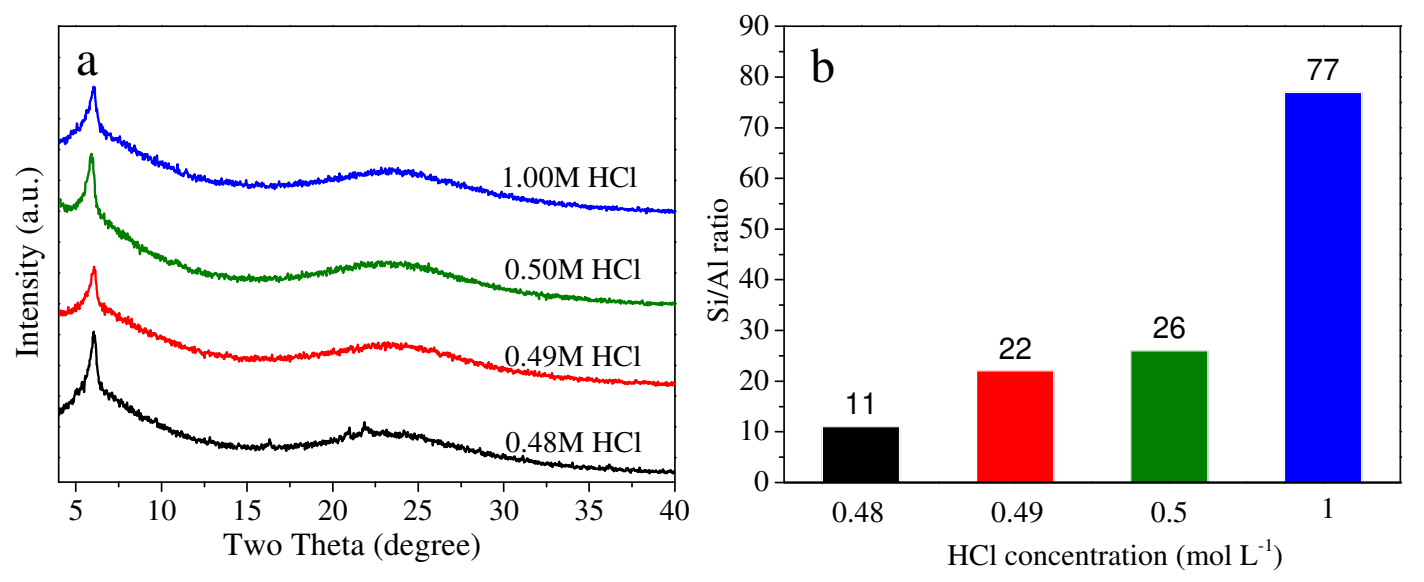

Fig. 1. XRD patterns (a) and Si/Al ratio of dealuminated zeolite L samples (b). 

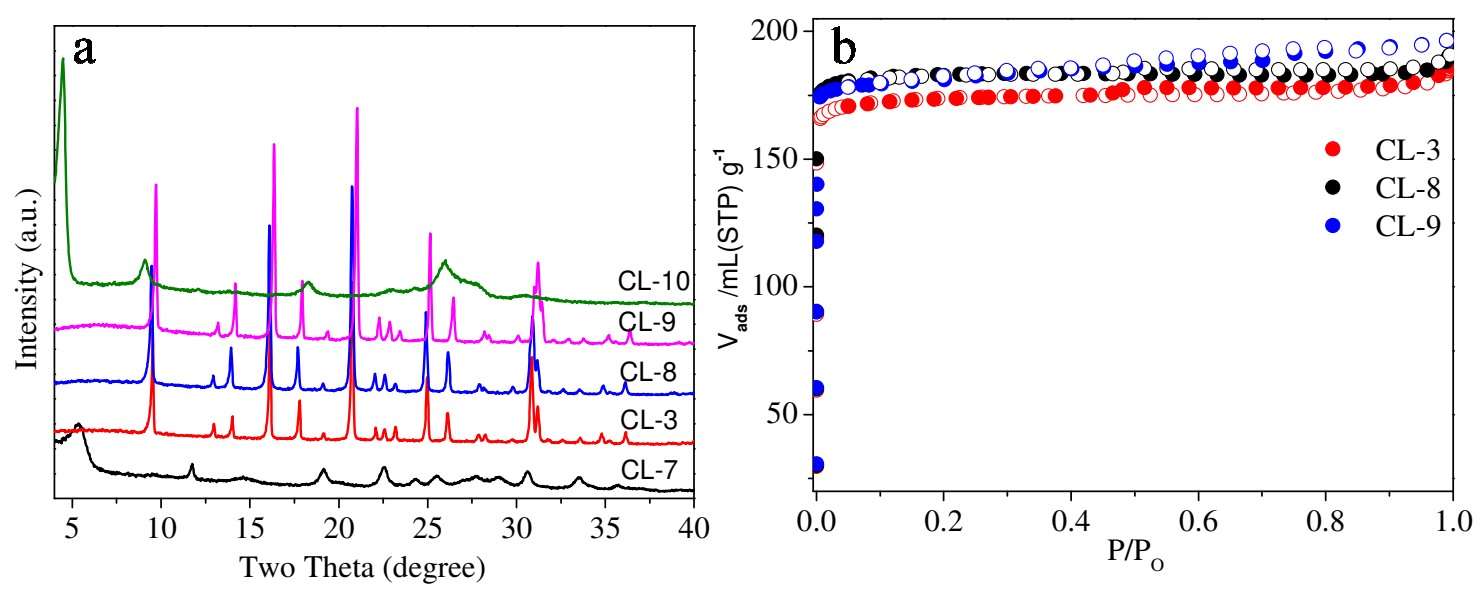

Fig. 2. XRD patterns (a) and $\mathrm{N}_{2}$ adsorption isotherms (b) of SSZ-13 samples obtained from dealuminated zeolite $\mathrm{L}$ at $150{ }^{\circ} \mathrm{C}$ for $24 \mathrm{~h}$. 

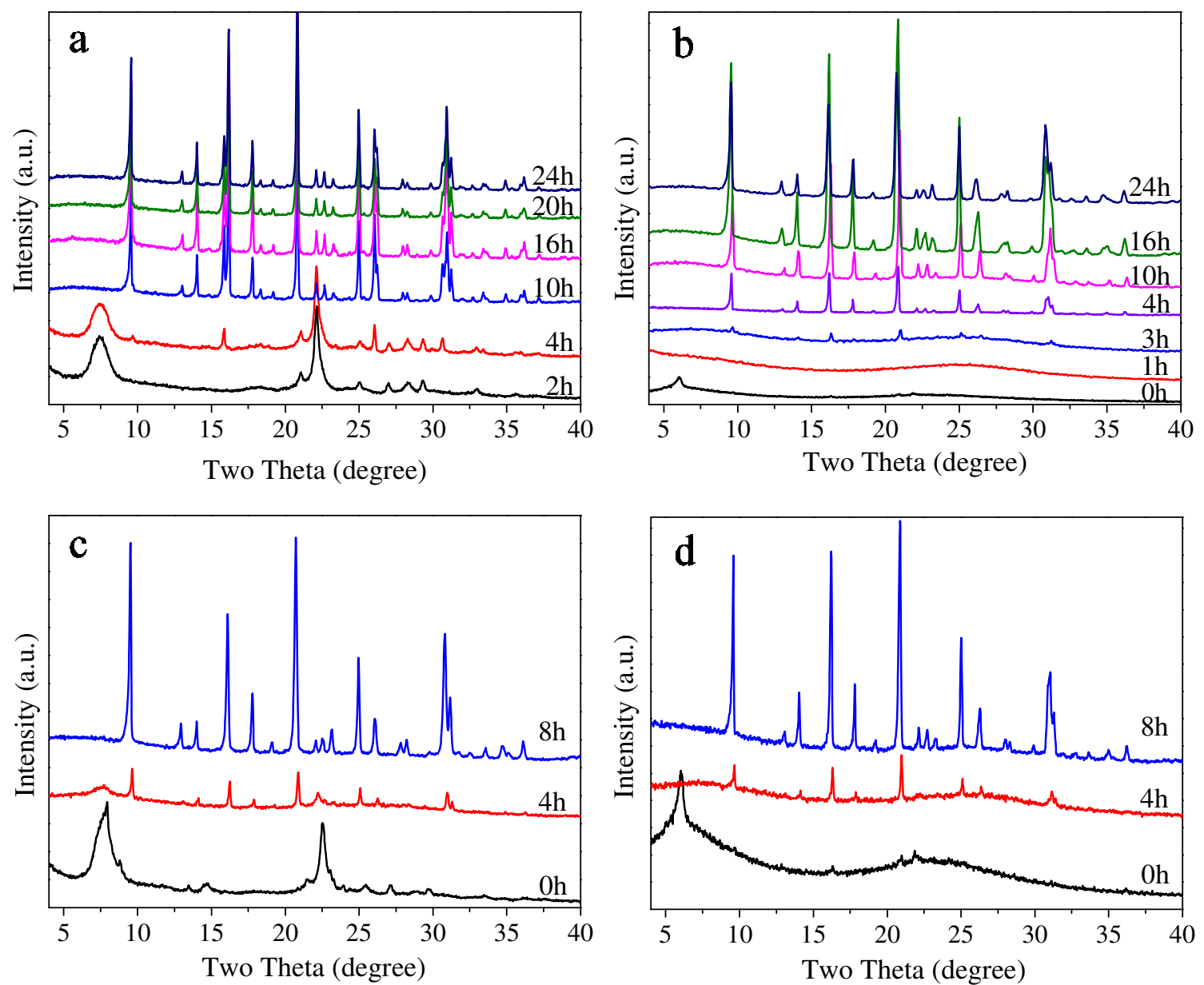

Fig. 3. XRD patterns of CB-3 (a) and CL-3 (b) synthesized at $150{ }^{\circ} \mathrm{C}$, and CB-6 (c) and CL-5 (d) synthesized at $180{ }^{\circ} \mathrm{C}$. 

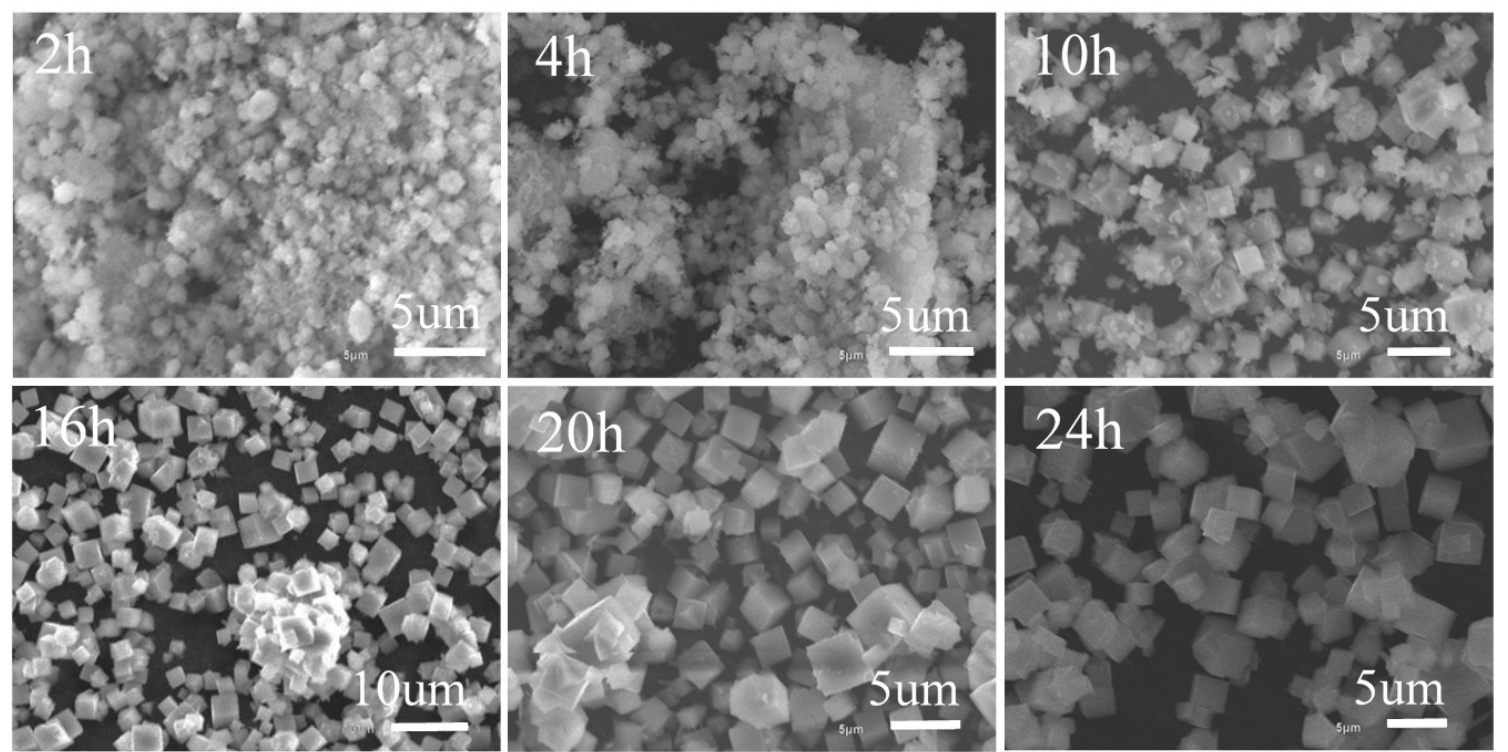

Fig. 4. SEM images of the products of zeolite Beta conversion to SSZ-13 (CB-3) at $150{ }^{\circ} \mathrm{C}$ for 2,4 , $10,16,20$, and $24 \mathrm{~h}$. 


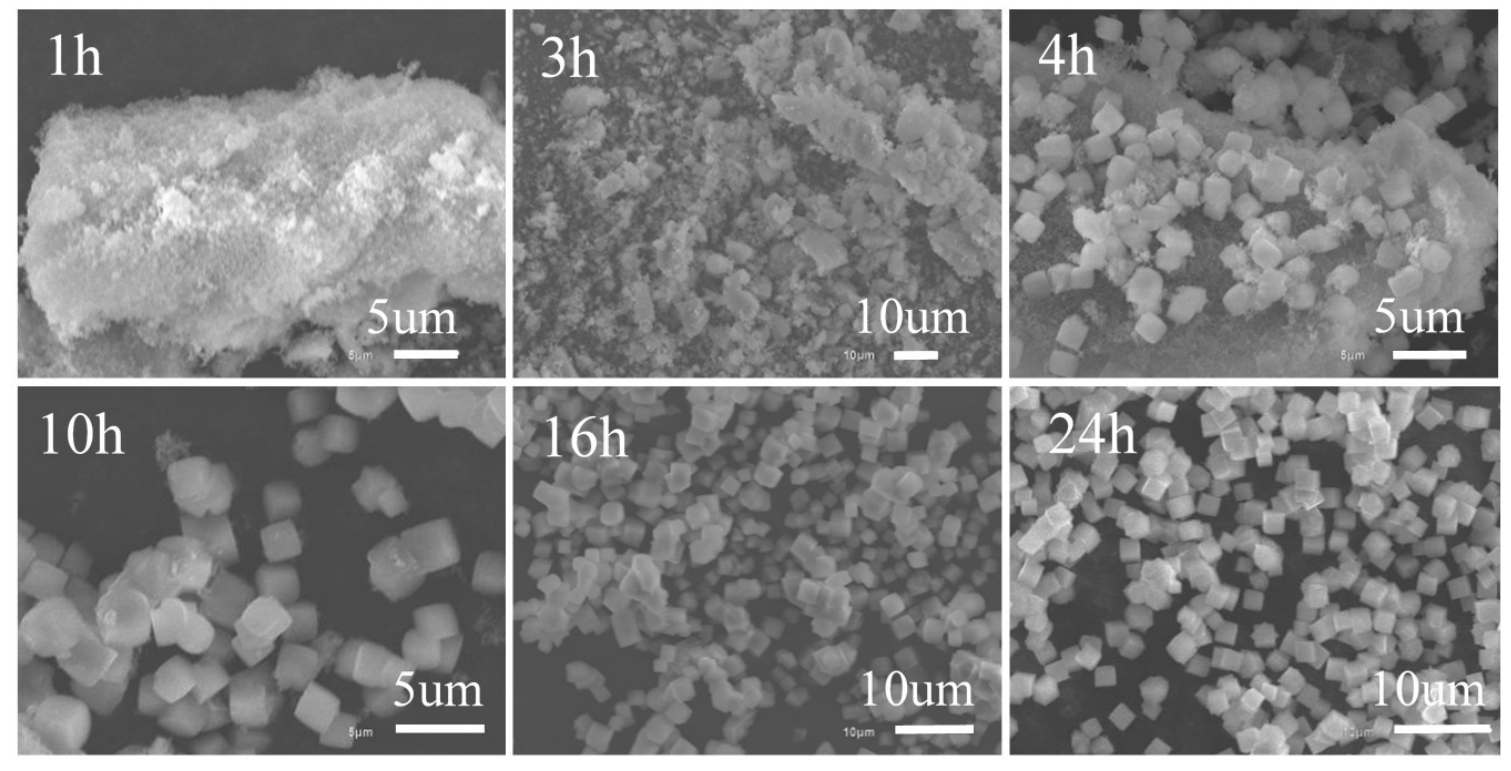

Fig. 5. SEM images of the products of zeolite L conversion to SSZ-13 (CL-3) at $150{ }^{\circ} \mathrm{C}$ for $1,3,4$, 10,16 , and $24 \mathrm{~h}$. 


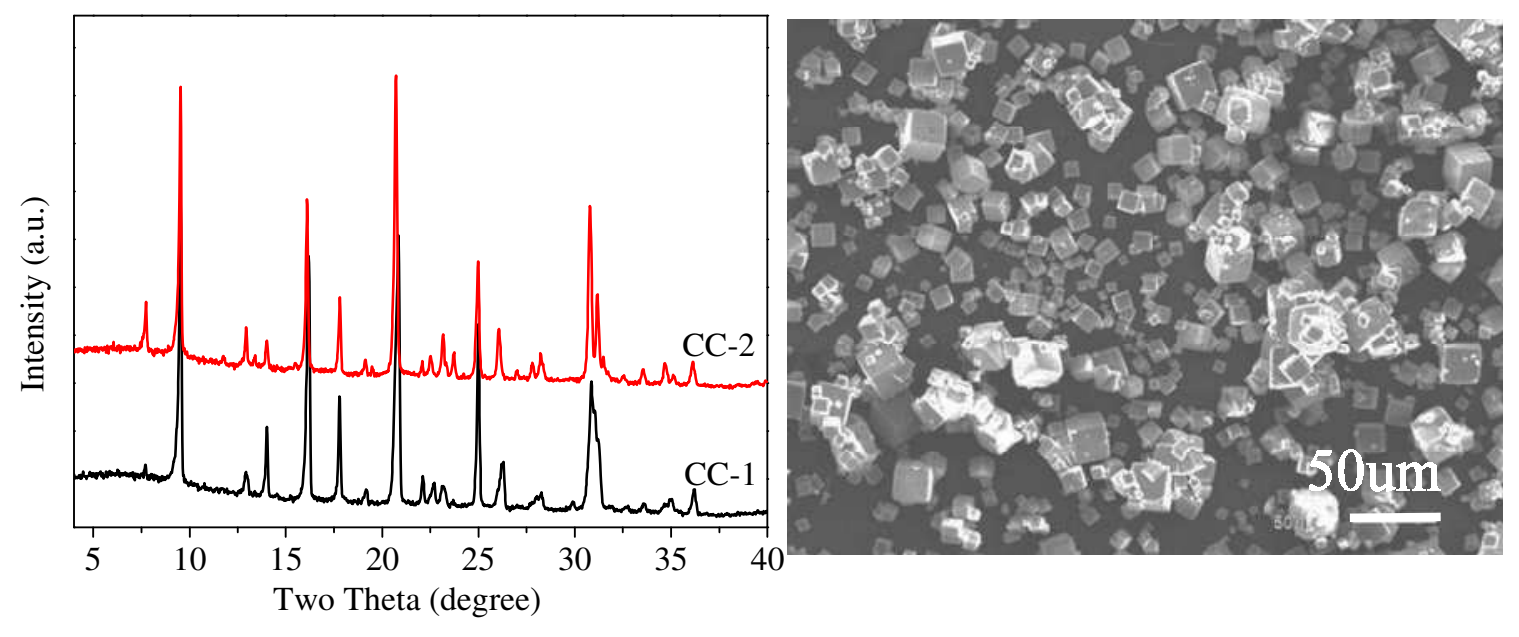

Fig. 6. XRD patterns (left) of two SSZ-13 samples synthesized from conventional reactants. Right:

SEM image of the CC-1 product. 


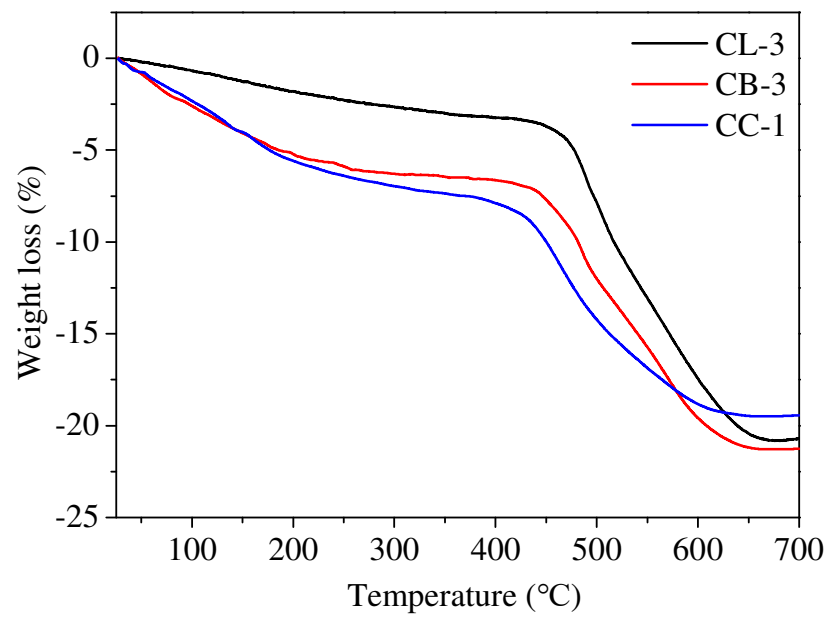

Fig. 7. Thermal analysis of SSZ-13 obtained from zeolite Beta (CB-3), zeolite L (CL-3) and conventional chemicals $(\mathrm{CC}-1)$ at $150{ }^{\circ} \mathrm{C}$. 

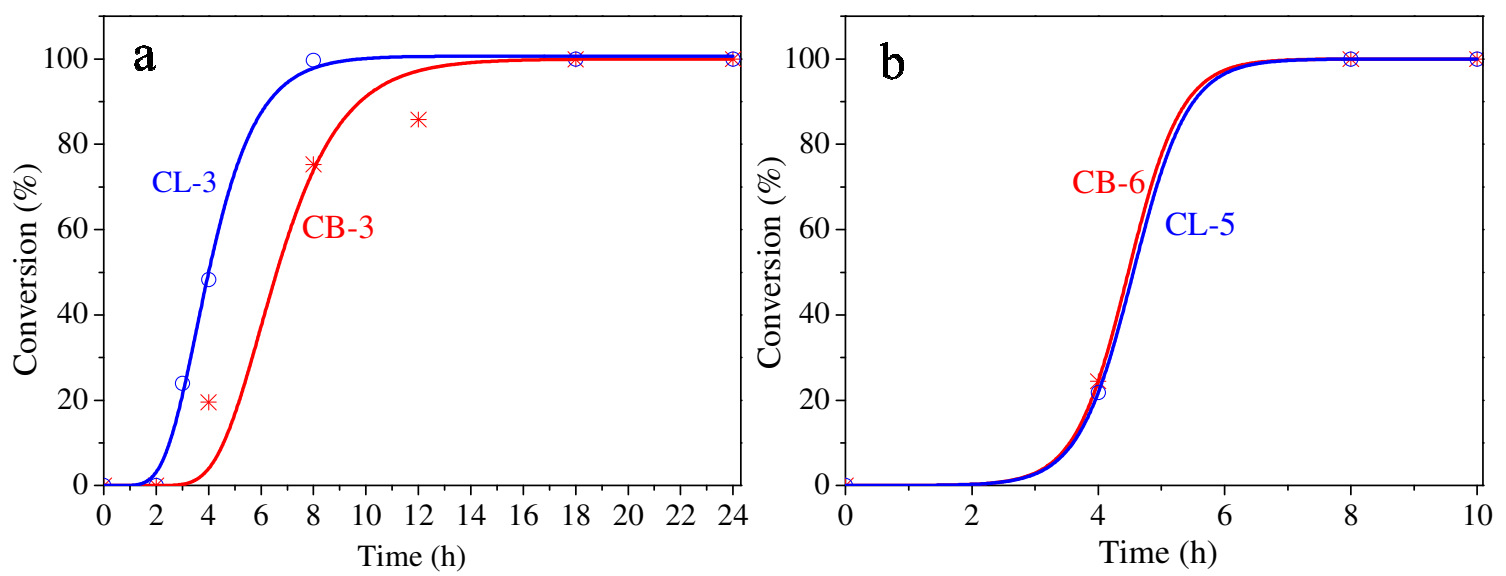

Fig. 8. SSZ-13 conversion rates at $150{ }^{\circ} \mathrm{C}$ (a) and $180{ }^{\circ} \mathrm{C}$ (b) using zeolite L (CL-3, CL-5) and zeolite Beta (CB-3, CB-6) as starting materials. 


\section{Tables}

Table 1. Synthesis conditions and physicochemical properties of the products obtained from zeolite L subjected to different levels of dealumination.

\begin{tabular}{|c|c|c|c|c|c|c|c|c|}
\hline \multirow{3}{*}{ Run } & \multicolumn{3}{|c|}{ *Synthesis conditions } & \multicolumn{5}{|c|}{ Product } \\
\hline & $\mathrm{Si} / \mathrm{Al}$ & $\mathrm{KOH} /$ & TMAD/ & Crystalline & Yield/ & $\mathrm{Si} / \mathrm{Al}$ & $S_{\mathrm{BET}} /$ & $V_{\text {mic }} /$ \\
\hline & & $\mathrm{SiO}_{2}$ & $\mathrm{SiO}_{2}$ & phase & $\%$ & & $\mathrm{~m}^{2} \mathrm{~g}^{-1}$ & $\mathrm{~cm}^{3} \mathrm{~g}^{-1}$ \\
\hline CL-7 & 3 & 0.38 & 0.26 & Zeolite L & 90 & 3 & - & - \\
\hline CL-3 & 11 & 0.38 & 0.26 & SSZ-13 & 38.5 & 6.7 & 526 & 0.26 \\
\hline CL-8 & 21 & 0.38 & 0.26 & SSZ-13 & 42 & 7.5 & 552 & 0.27 \\
\hline CL-9 & 26 & 0.38 & 0.26 & SSZ-13 & 40 & 16 & 550 & 0.26 \\
\hline CL-10 & 77 & 0.38 & 0.26 & $\begin{array}{l}\text { Layered } \\
\text { silicate }\end{array}$ & 43 & - & - & - \\
\hline
\end{tabular}

*The synthesis is performed at $150{ }^{\circ} \mathrm{C}$ for $24 \mathrm{~h}$. 
Table 2. Experimental conditions, crystalline products and yields of SSZ-13 obtained from zeolite Beta, zeolite L, and conventional reactants.

\begin{tabular}{|c|c|c|c|c|c|c|c|}
\hline Sample & $\mathrm{Si} / \mathrm{Al}$ & $\begin{array}{l}\mathrm{KOH} / \\
\mathrm{SiO}_{2}\end{array}$ & $\begin{array}{l}\text { TMAD/ } \\
\mathrm{SiO}_{2}\end{array}$ & $\begin{array}{l}\text { Temperature/ } \\
{ }^{\circ} \mathrm{C}\end{array}$ & $\begin{array}{l}\text { Time/ } \\
\mathrm{h}\end{array}$ & $\begin{array}{l}\text { Crystalline } \\
\text { Product(s) }\end{array}$ & $\begin{array}{l}\text { Yield/ } \\
\%\end{array}$ \\
\hline CB-1 & 11 & 0.60 & 0.31 & 150 & 24 & SSZ-13 + MOR & - \\
\hline CB-2 & 11 & 0.50 & 0.31 & 150 & 24 & SSZ-13 + MOR & - \\
\hline $\mathrm{CB}-3$ & 11 & 0.36 & 0.31 & 150 & 24 & SSZ-13 & 59 \\
\hline CB-4 & 11 & 0.20 & 0.31 & 150 & 24 & Beta & - \\
\hline CB-5 & 11 & 0.36 & 0.31 & 180 & 4 & Beta + SSZ-13 & - \\
\hline CB-6 & 11 & 0.36 & 0.31 & 180 & 8 & SSZ-13 & 45 \\
\hline CB-7 & 11 & 0.36 & 0.31 & 180 & 10 & SSZ-13 & 48 \\
\hline CL-1 & 11 & 0.20 & 0.31 & 150 & 24 & Layered silicate & - \\
\hline CL-2 & 11 & 0.30 & 0.26 & 150 & 24 & SSZ-13 + L & - \\
\hline CL-3 & 11 & 0.38 & 0.26 & 150 & 24 & SSZ-13 & 53 \\
\hline CL-4 & 11 & 0.38 & 0.26 & 180 & 4 & Amorp.+ SSZ-13 & - \\
\hline CL-5 & 11 & 0.38 & 0.26 & 180 & 8 & SSZ-13 & 50 \\
\hline CL-6 & 11 & 0.38 & 0.26 & 180 & 10 & SSZ-13 & 51 \\
\hline CC-1 & 11 & 0.36 & 0.26 & 150 & 72 & SSZ-13 + MOR & 70 \\
\hline $\mathrm{CC}-2$ & 11 & 0.38 & 0.31 & 150 & 72 & SSZ-13 + MOR & 66 \\
\hline
\end{tabular}


Table 3. The impact of different alkaline metal cations on the formation of SSZ-13 from zeolite Beta and zeolite $\mathrm{L}$ at $150{ }^{\circ} \mathrm{C}$ for $24 \mathrm{~h}$.

\begin{tabular}{|c|c|c|c|c|c|c|}
\hline \multirow{2}{*}{$\begin{array}{l}\text { Alkaline cation } \\
\text { (M) }\end{array}$} & \multicolumn{3}{|c|}{ Synthesis conditions } & \multicolumn{3}{|c|}{ Product } \\
\hline & $\mathrm{Si} / \mathrm{Al}$ & $* \mathrm{MOH} / \mathrm{SiO}_{2}$ & $\mathrm{TMAD} / \mathrm{SiO}_{2}$ & Crystalline phase & Yield/ \% & $\mathrm{Si} / \mathrm{Al}$ \\
\hline CB-Li & 11 & 0.36 & 0.31 & Beta + Unknown & --- & --- \\
\hline $\mathrm{CB}-\mathrm{Na}$ & 11 & 0.36 & 0.31 & SSZ-13 & 50 & 5.7 \\
\hline $\mathrm{CB}-\mathrm{K}$ & 11 & 0.36 & 0.31 & SSZ-13 & 43.5 & 7.2 \\
\hline $\mathrm{CB}-\mathrm{Cs}$ & 11 & 0.36 & 0.31 & Pollucite & --- & --- \\
\hline CL-Li & 11 & 0.38 & 0.26 & Unknown & --- & --- \\
\hline CL-Na & 11 & 0.38 & 0.26 & SSZ-13 & 50 & 7 \\
\hline CL-K & 11 & 0.38 & 0.26 & SSZ-13 & 43.5 & 6.7 \\
\hline CL-Cs & 11 & 0.38 & 0.26 & Pollucite & --- & --- \\
\hline
\end{tabular}

*M - Li, Na, K, Cs 
Zeolite Beta
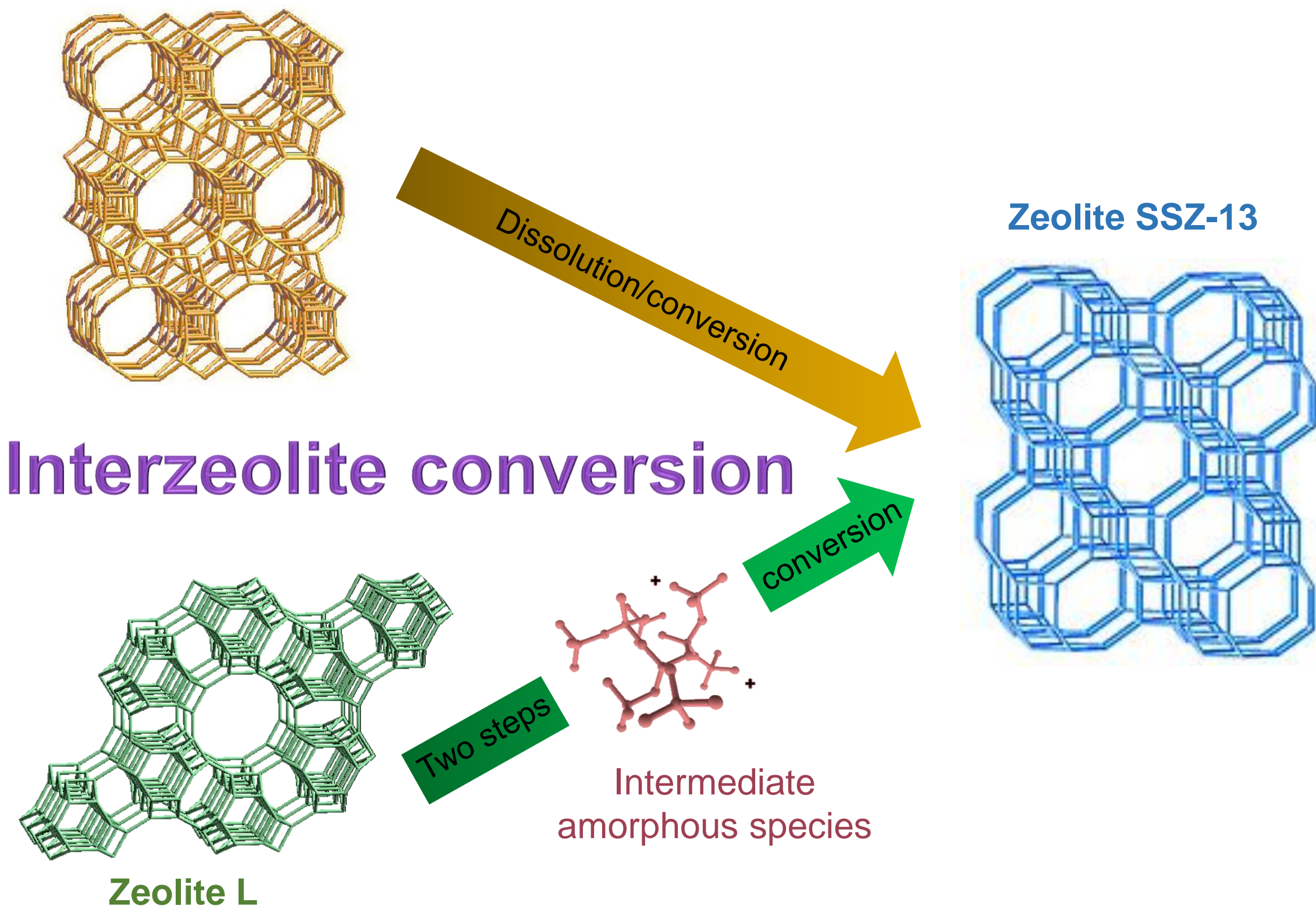